\title{
PERSPECTIVAS DA EDUCAÇÃO AMBIENTAL NA FRONTEIRA OESTE DO RIO GRANDE DO SUL
}

\author{
Márcio Tavares Costa ${ }^{1}$ \\ Mariseti Tibinkowski Costa ${ }^{2}$ \\ Siderly do Carmo Dahle de Almeida ${ }^{3}$
}

Resumo: $O$ trabalho expõe informações básicas em relação à Educação Ambiental nas escolas. Os dados foram coletados através de um questionário aplicado a 72 professores. Abrangidas as cidades de Itaqui, Uruguaiana e São Borja; conhecidas por pertencerem à Fronteira Oeste do Rio Grande do Sul. Os resultados indicam que aproximadamente $60 \%$ dos docentes consideram-se preparados para aplicar o tema em suas classes, bem como, um percentual de $70 \%$ que se atualizaria para isso, independente do diagnóstico como aptos ou não em relação ao tema. O Bioma Amazônico é o ecossistema mais enfatizado nas escolas. Os quase $90 \%$ dos entrevistados que promovem a Educação Ambiental apontam seus colegas como os que menos aceitam esta atitude.

Palavras-chaves: Meio ambiente; Escola; Professor.

1Universidade Federal do Pampa. E-mail: marciocosta@unipampa.edu.br 2Fundação Universidade Federal do Rio Grande. E-mail: zetitc@gmail.com ${ }^{3}$ Centro Universitário Cesumar. E-mail: siderly.barbosa@ead.cesumar.br

Revbea, São Paulo, V. 9, № 2: 200-213, 2014. 


\section{Introdução}

Cresceu muito nas últimas décadas a consciência do homem como sendo parte da natureza, e para garantir uma mínima qualidade de vida para as futuras gerações cabe conservá-la. Nesse esforço para preservação do meio ambiente surgiram diferentes comprometimentos nos diversos segmentos da sociedade. Na Educação, a Educação Ambiental (EA) assumiu a responsabilidade de disseminar o conhecimento sobre o ambiente e construir valores, habilidades, atitudes, objetivando o desenvolvimento de uma comunidade sustentável através do despertar da preocupação individual e coletiva para essa questão. Nos dias atuais este assunto deve estar presente, de forma articulada, em todos os níveis e modalidades do processo educativo, em caráter formal e não-formal. Sendo, deste modo, protegido pela Constituição Federal (BRASIL, 1988) e pela lei №. 9.795 (1999).

A crise ambiental que vivenciamos aponta a EA como alicerce para enfrentar este problema. E a escola é vista pela sociedade como lócus para sua realização. Na educação formal, em particular, a temática já está presente, de alguma forma, em praticamente todas as escolas, como apontam pesquisas recentes (2004 e 2006) realizadas pelo Instituto Nacional de Estudos e Pesquisas Educacionais (INEP). Porém, o cenário é de uma minoria de pedagogos que movimentam iniciativas para incorporar o assunto na agendaescolar de forma espontânea. Espontaneamente, pois, não há imposição da EA como conteúdo programático. Embora os subsídios para os professores programarem essa determinação estejam nos Parâmetros Curriculares Nacionais (PCN), os quais apresentam aos professores diretrizes educacionais nacionais de reflexão sobre o trabalho com os alunos e, também, diretrizes para a ação.

No Brasil, cada indivíduo produz entre 0,5 e 1 quilo de lixo por dia, deste cerca de 50\% do lixo é composto por matéria orgânica (SILVA; SILVA, 2010). Panorama favorável para implantar, por exemplo, um programa de utilização destes resíduos nas escolas. Isso seria possível em todos os estabelecimentos de ensino, se a questão ambiental apresentasse uma proporção maior. Levando em consideração a quantidade de resíduos produzidos por uma pessoa ao longo de um dia, e multiplicarmos pelos quase 200 milhões de habitantes brasileiros (IBGE, 2007), resultaria em mais de 100 milhões de matéria residual diária. Saturando os lixões e aterros nacionais, pois os atos de coleta seletiva e reciclagem ainda são insignificantes. Caso houvesse a consciência da transformação do lixo molhado em material benéfico através da compostagem ou utilizando minhocas neste processo, a vida útil dos depósitos de lixo aumentaria, e amenizaria alguns problemas graves nos dias atuais, como espaço, doenças, infertilidade dos solos, entre outros.

Neste contexto, este trabalho visou criar uma expectativa do quadro docente, de Ensino Fundamental e Médio, da região a respeito da EA, somando-se na busca de novas ferramentas para um futuro mais sustentável. Estão inclusas no estudo as cidades de Uruguaiana, Itaqui e São Borja, as três 
localizadas no extremo oeste do Rio Grande do Sul. Assim, levantou-se através de dados documentais a alíquota de educadores que se consideram aptos a aplicar o assunto em sala de aula; aqueles que estariam dispostos a realizar um curso de atualização; os docentes que aplicam na rotina escolar a EA; a aceitação desta posição pelos colegas de serviço e pelos alunos; a porção dos profissionais que estão cientes dos objetivos e normas que regem a $E A$; 0 percentual de professores que considera importante a Educação Ambiental, divididos por áreas de atuação; além do Bioma Brasileiro mais valorizado pela categoria.

Com dados como esses é possível criar uma rede de professores interessados em aplicar a EA no cotidiano de seu ambiente de trabalho. De forma a fortalecer os laços entre os educadores. O que estimulará a promoção da EA nas diferentes disciplinas do ensino. Com isso, em paralelo, tende a haver um acréscimo de docentes adeptos. E de tal modo, diminuir o impacto desta classe, tímida, ao iniciar uma atividade. Em que muitas vezes se encontra rompendo a prática pedagógica tradicional e hegemônica no cotidiano escolar. E, por isso, sofrendo com inúmeras críticas, má vontade e mesmo pressões.

O questionário foi aplicado a setenta e dois professores escolhidos aleatoriamente. Compreendendo oito escolas, também escolhidas de forma casual, ao longo das cidades visitadas. Processado a fim de obter informações básicas sobre os profissionais da área e analisado com o suporte de gráficos, tabela e diagrama.

O presente trabalho ergue a hipótese de capacitação, se de interesse, dos professores. Sendo esse, um futuro possível para este projeto. Além de servir de um potencial alicerce para estudos e atividades similares nas localidades.

\section{Perspectivas da educação ambiental na fronteira oeste do Rio Grande do Sul}

O desenvolvimento da EA no Brasil baseia-se na Constituição Federal de 1988, mais especificamente nos artigos 205 e 225. Estes tópicos falam que "A educação, direito de todos e dever do Estado e da família, será promovida e incentivada com a colaboração da sociedade, visando ao pleno desenvolvimento da pessoa, seu preparo para o exercício da cidadania e sua qualificação para o trabalho" e que "Todos têm direito ao meio ambiente ecologicamente equilibrado, bem de uso comum do povo e essencial à sadia qualidade de vida, impondo-se ao Poder Público e à coletividade o dever de defendê-lo e preservá-lo para as presentes e futuras gerações", respectivamente. $\mathrm{O}$ primeiro se refere à Educação e o segundo ao Meio Ambiente.

A lei $n^{\circ} 9.795$, de abril de 1999 é mais profunda, voltada especificamente 
atitudes e competências voltadas para a conservação do meio ambiente, bem de uso comum do povo, essencial à sadia qualidade de vida e a sua sustentabilidade". Encarrega às instituições educativas de promover a EA de forma integrada aos seus programas de ensino. $E$ estabelece que 0 desenvolvimento do tema deva ser de forma interdisciplinar, inibindo sua aplicação como disciplina específica.

O rompimento com o ensino escolar tradicional a fim de começar a desenvolver o assunto de forma interdisciplinar é a maior barreira para os educadores. Mas existem diferentes maneiras de trabalhar o tema. No Brasil, há registros sobre iniciativas isoladas de inserção de temas ambientais no ensino formal a partir da década de 1950. Em sua maioria, eram atividades realizadas por professores do ensino básico e do ensino superior, que saíam das salas de aula com seus alunos para observar e estudar o ambiente que circundava a escola, o bairro, a cidade. Saídas que alguns chamavam de "estudos do meio" ou "trabalho de campo". Segundo Seniciato e Cavassari (2004), as aulas de campo constituem uma metodologia educativa eficaz, uma vez que aliam envolvimento e motivação dos alunos com a superação da fragmentação do conhecimento, tornando mais significativa a aprendizagem dos conhecimentos científicos. Além disso, permitem uma abordagem ao mesmo tempo mais complexa e menos abstrata dos fenômenos estudados, favorecendo a manifestação de sensações e emoções dos alunos. Porém, a aula de campo exige que o professor esteja muito bem preparado, para que possa atingir seus objetivos.

Outro exemplo é o trabalho com temas geradores. Citando a água como tema gerador, ela pode ser tratado pela Biologia, como fonte de vida e seu comportamento no organismo; pela Química, através da poluição, tratamento, propriedades físicas e químicas, $\mathrm{pH}$, soluções e reações; pela Educação Artística como música ou peça de teatro; pela Língua Portuguesa com interpretações de texto; pela Geografia, com a distribuição das águas; pelo Ensino Religioso, como o equilíbrio do ser; pela Educação Física, com a necessidade da água pelo corpo e; pela Língua Inglesa com tradução de textos (KRÜGER e LOPES, 1997).

No cenário internacional, eventos elaboram ações em prol da $\mathrm{EA}$. Na Conferência Intergovernamental de Tbilisi em 1977, na Geórgia, a EA foi definida como uma dimensão dada ao conteúdo e à prática da educação, orientada para a resolução dos problemas concretos do meio ambiente, por meio de enfoques interdisciplinares e de uma participação ativa e responsável de cada indivíduo e da coletividade (DIAS, 1993). Nos seus princípios constam: o processo dinâmico integrativo e a realidade transformadora, participativa, abrangente, globalizadora, permanente e contextualizada.

$E$ nestes tempos em que a informação assume um papel cada vez mais relevante, ciberespaço, multimídia, internet, a educação para a cidadania representa a possibilidade de motivar e sensibilizar as pessoas para transformar as diversas formas de participação na defesa da qualidade de vida 
(JACOBI, 2003). Com uma postura mais responsável por parte da população, a solução para a problemática da sustentabilidade fica mais próxima.

Nesse contexto, segundo Reigota (1998), a EA aponta para propostas pedagógicas centradas na conscientização, mudança de comportamento, desenvolvimento de competências, capacidade de avaliação e participação dos educandos. Assim, pesquisas envolvendo EA diretamente nas escolas são de significativa importância para a sociedade, porque podem verificar se a temática chega até estas instituições e identificar dificuldades e possíveis melhorias são de significativa importância para a sociedade.

\section{Metodologia de pesquisa}

Com o intuito de dar prosseguimento aos primeiros passos na direção do despertar da consciência dos jovens, este projeto traz, através de questionário (APÊNDICE), uma visão da EA nas escolas por meio dos professores. $O$ documento apresenta dez indagações, das quais nove tem respostas objetivas, eliminando ao máximo a subjetividade. As questões abrangem a esfera administrativa a qual 0 docente pertence; as disciplinas dadas; 0 desenvolvimento da EA na sua cadeira; se os professores têm conhecimento que o zelo pela EA é defendido pela legislação; e como o educador se considera quanto a este tema, apto ou não a desenvolver este assunto em suas aulas; entre outras. Todas as pessoas questionadas são mantidas no anonimato.

As modalidades disciplinares de cada professor estão classificadas de acordo com a área. Disciplinas como Biologia, Química e Geografia pertencem à classe "Ciências Naturais"; História, Estudo da Religião, Educação Artística e Português estão em "Ciências Sociais"; Educação Física enquadra-se em "Ciências da Saúde"; e "Ciências Exatas", contém a Matemática e Física.

Para o desenvolvimento desta pesquisa foram visitadas oito escolas de Ensino Fundamental e Médio, escolhidas de forma aleatória nas cidades de Uruguaiana, Itaqui e São Borja, localidades pertencentes à Fronteira Oeste do Rio Grande do Sul. O Pampa é o bioma predominante destas regiões. O número de amostra foi de setenta e dois professores do Ensino Fundamental e Médio. Sendo analisados os dados de vinte e quatro docentes de cada cidade.

As coletas das amostras duraram quatro meses, com início em agosto de 2010, e término em novembro do mesmo ano. Em agosto foram visitadas três escolas em Itaqui, uma de Ensino Fundamental e duas de Ensino Fundamental e Médio. Setembro houve a visita a duas escolas de São Borja de Ensino Fundamental e Médio. Em Outubro, houve a aplicação do questionário em uma escola de Ensino Fundamental de São Borja. E, em novembro, duas escolas de Uruguaiana colaboraram com o trabalho, uma de Ensino Fundamental e outra de Ensino Fundamental e Médio. 
De posse dos dados, estes foram analisados, principalmente em forma de gráficos e diagrama, para alcançar o almejado resultado ao qual se propõe o estudo, e facilitar a compreensão do que está sendo exposto. Os gráficos utilizados foram o de caixa 3D e um em forma de pizza. Juntamente com um diagrama.

\section{Resultados e discussão}

A coleta de dados foi somente via documental, elaborada com base em uma série de indagações voltadas a Educação Ambiental e sua aplicação nas aulas. A colaboração da escola e dos professores foi e é essencial para este tipo de consulta. Não há como negar que a maioria absoluta das escolas foi atenciosa, bem como seus professores. Porém, a preocupação deve estar naquelas instituições que rejeitaram o estudo, acreditando se tratar de uma avaliação da mesma, apesar de exaustivas explicações sobre o que abordava o trabalho.

Embora existam basicamente três formas de desenvolver a EA nas escolas, não houve diferenciação entre Projetos, Disciplinas Específicas ou Inserção da Temática Ambiental nas Disciplinas. Pois a intenção é retratar o fato de ter ou não a temática no colégio procurado. Contudo, após análise dos resultados, várias correlações podem ser corroboradas.

Foi evidenciado (questões 1, 2 e 7) que a maioria dos profissionais que se consideram despreparados em relação ao assunto trabalha com o Ensino Fundamental. Totalizando $22,31 \%$ dos professores, contra $16,8 \%$ enquadrados no Ensino Médio (Fig. 1). Entretanto, todos entrevistados do Ensino Médio estariam dispostos a realizar um curso de atualização sobre o assunto, enquanto que do quadro do Ensino Fundamental, apenas 50\% estariam com esta determinação. Deve-se levar em consideração que os entrevistados que atuam somente no Ensino Fundamental chega a 50\%, e no Ensino Médio soma-se 39\%, com uma intersecção de $11 \%$.

Esse efeito demonstra o desinteresse dessa parcela significante de educadores, atuantes na base escolar, em atualizarem-se. Os motivos são vários, falta de reconhecimento da categoria, excesso de alunos em sala de aula, agressões e/ou desrespeito por parte dos alunos, falta de estrutura física na instituição, entre muitas outras. Consequentemente, este fato deixa uma lacuna na ideia de formação continuada. E, ao considerar a afirmação, de Adams e Tillotson (1995, apud CUNHA e KRASILCHIK, 2001) que "a preparação do professor de Ciências é hoje reconhecida como o ponto crítico na reforma da educação em Ciência"; somada a avaliação de Garrido e Carvalho (1995) dos cursos de formação de professores, tanto aqueles destinados à sua preparação, como aqueles voltados para a sua atualização, como sendo insatisfatórios, nota-se um buraco na educação.

Quando levantada a discussão sobre qual Bioma Continental Brasileiro (IBGE, 2004) seria o mais importante a ser enfatizado numa sala de aula, 
quando cabível (questão 9), o destaque foi para a Amazônia, com 33,5\% dos votos (Fig. 2). Seguida pelo Bioma Pampa (27,5\%), Mata Atlântica (12\%), Pantanal (9\%), Caatinga e Cerrado (6\%). Com 6\% de abstenções. Implicação questionável, já que qualquer uma das três cidades visitadas pertence ao Bioma Pampa, com uma forte influência da tradição gaúcha.

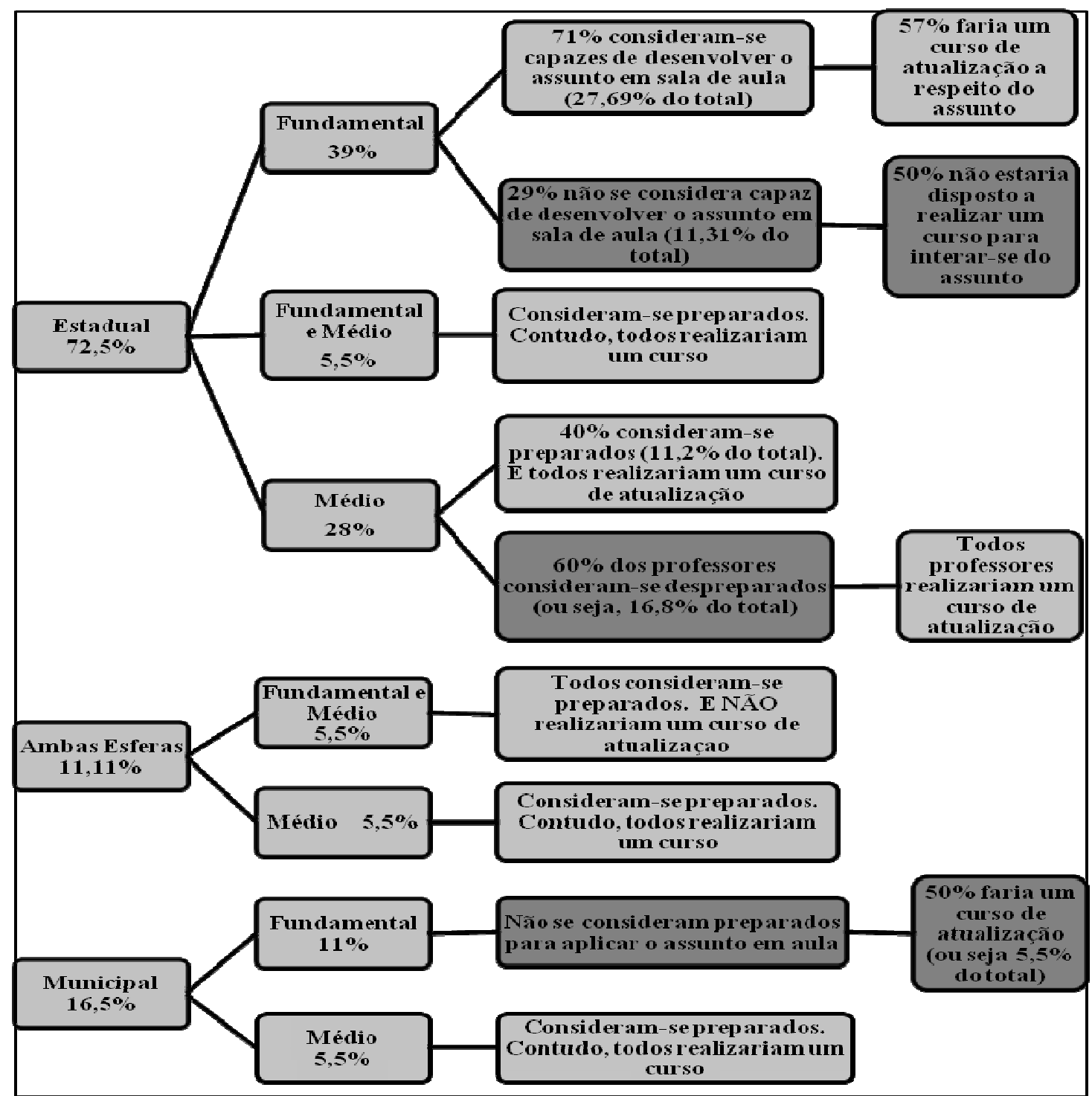

Figura 1: Diagrama demonstrando, em percentual, a quantia de professores inseridos nas diferentes esferas administrativas, nível escolar e posição quanto ao tema tratado. Com ênfase nos que se consideram despreparados.

Os Parâmetros Curriculares Nacionais (PCN) oferecem total flexibilidade e liberdade para temas transversais, como a Educação Ambiental. No entanto, um dos objetivos de sua formação foi a de respeitar as diversidades regionais. Assim, alicerçado no PCN, o Bioma prioritário na maior parte do Rio Grande do Sul deveria ser o Pampa. 
São conhecidas as dificuldades dos docentes em aplicar, independente da forma, a EA. Em pesquisas como a de Travassos (2006), sobre a prática da EA nas escolas, a falta de tempo dos professores está dentre as maiores dificuldades com 45,8\% de citações em seus entrevistados. Para Corrêa et al. (2006), a falta de tempo é totalmente dependente dos baixos salários. Para que um professor tenha uma renda "razoável" deve trabalhar em duas ou três escolas. Neste ponto de vista, Viana e Oliveira, 2006, expõe que a melhoria dos salários, bem como o investimento na formação continuada desses profissionais e uma jornada de trabalho adequada, são elementos necessários para a valorização do trabalho docente.

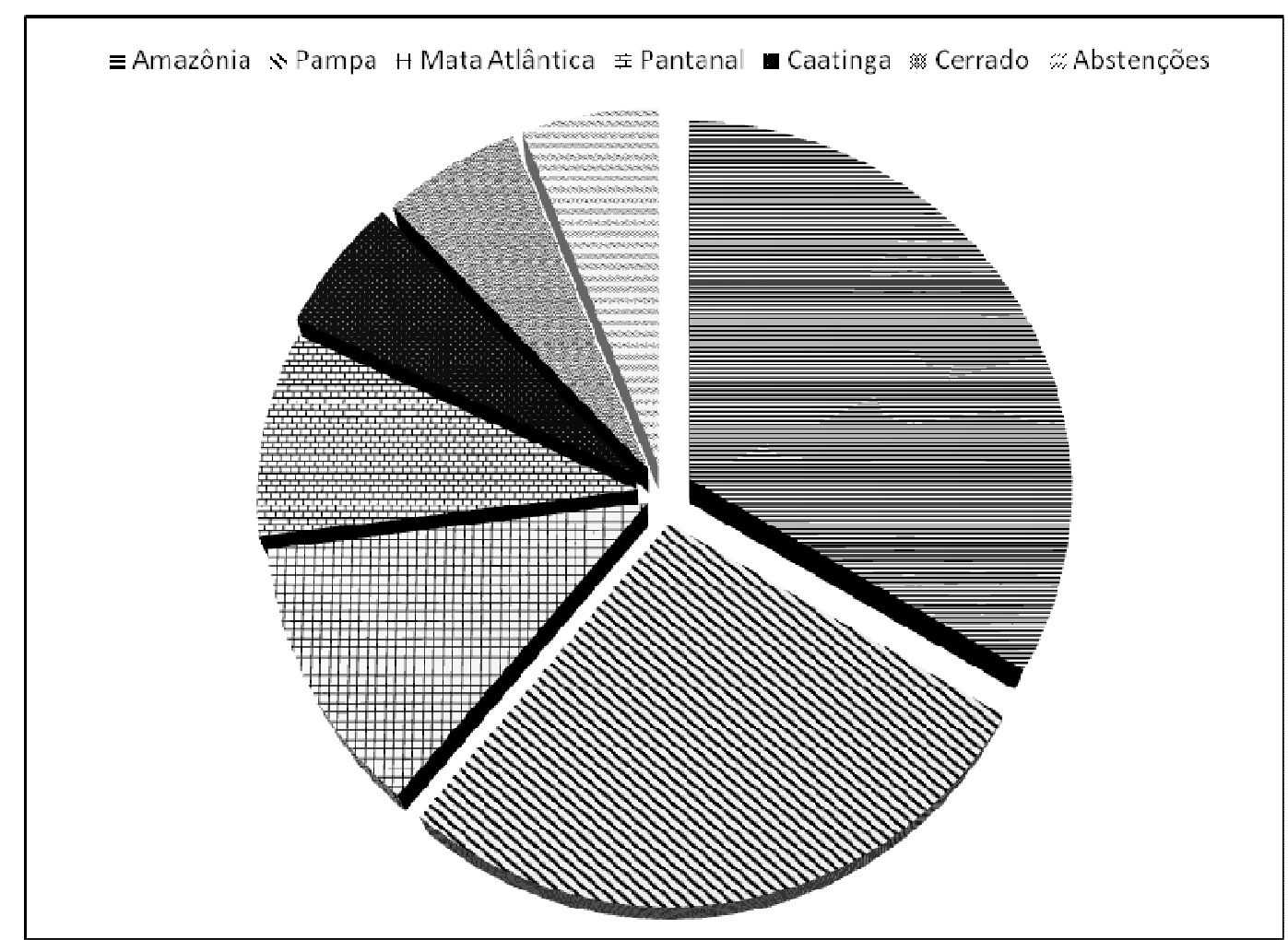

Figura 2: Gráfico com ilustração dos ecossistemas mais valorizados em sala de aula pelos professores.

Apesar dos problemas, os resultados são positivos, e mostram que a imensa maioria (89\%) dos educadores aplica a EA em suas aulas (questão 8). Neste trabalho não foi levantada a idade dos voluntários, mas de acordo com Bispo e Oliveira (2007), a idade dos professores é um indicador fundamental para o trabalho em EA, uma vez que esse é um dos elementos que pode contribuir para a construção das representações especificidades (preservacionista e/ou mais crítica) do meio ambiente, sendo importante na caracterização do mundo dos professores em atuação. Em um comparativo entre a aceitação dos alunos e dos colegas de trabalho, vemos um menor 
consentimento por parte dos companheiros de profissão (Fig. 3). Compatível, de certo modo, com o que sugere Biondo et al. (2010):

A pouca adesão dos colegas professores nos projetos foi colocada como uma das principais dificuldades, sendo que ela pode estar relacionada a vários aspectos. Um dos principais seria a falta de referencial teórico (a qual possibilitaria uma maior capacidade de envolvimento nas atividades) não obtida na formação universitária inicial, que em muitos casos não prepara o futuro professor para a complexidade da dimensão ambiental. Além disto, grande parte dos professores de educação básica convive com o pouco incentivo e estímulo de sua profissão.

No total, $16,5 \%$ dos entrevistados classificaram a aceitação da categoria como "Ruim" ou "Regular", em contrapeso, os alunos tiveram 5,5\% dos votos. Aqueles que consideram a aceitação do grupo escolar como "Boa" ou "Ótima" somam-se $72,5 \%$; os alunos obtiveram $83,5 \%$, indicando que estes últimos apreciam melhor uma aula de EA.

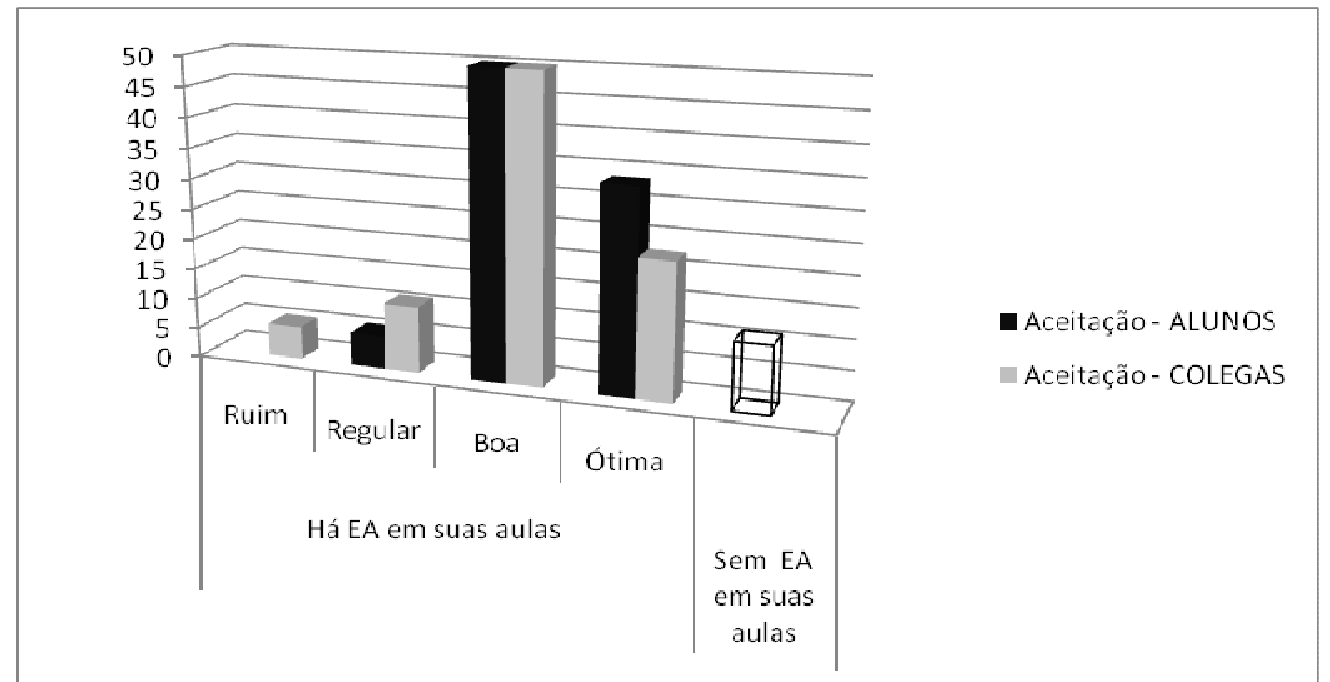

Figura 3: Gráfico de caixa demonstrando o percentual de professores que aplicam em suas aulas EA. E a distribuição da aceitação por eles votada.

Seguindo análise (questões 3, 4, 5 e 6), o estudo mostra que independente da área de atuação do professor, todos estão de acordo com a importância dada, nos dias atuais, à EA. Aqueles que desempenham suas atividades no campo das ciências naturais, da saúde e séries iniciais estão cientes do objetivo da EA. Entre os conhecedores do alicerce legal sobre a EA, os da área da saúde e das séries iniciais são os mais informados (Tabela 1).

Esse ponto multidisciplinar aparece, pois como Garcia (2000, apud trabalhar o conhecimento buscando uma reintegração de aspectos que ficaram Revbea, São Paulo, V. 9, N²: 200-213, 2014. 
isolados uns dos outros pelo tratamento disciplinar". Desta forma, sugere que por meio da interdisciplinaridade seja possível haver uma melhor aproximação dos complexos fenômenos naturais e sociais. $O$ autor ressalta ainda que não é oferecido um "pacote pronto às escolas", mas que cada uma deve estruturar o seu programa de ensino no contexto da escola e da comunidade, e que isso consiste em uma grande responsabilidade a qual requer o envolvimento de toda a comunidade escolar.

Por fim, alguns docentes citaram, quando pedido sua contribuição sobre algo que deveria mudar/melhorar quando abordamos EA que (questão 10)

"A educação ambiental é um assunto interdisciplinar, de grandeza profunda se bem aproveitada, os resultados podem não ser imediatos, mas a conscientização tem que ser presente, para que possamos colher frutos no futuro bem próximo. Devemos mudar no fato de "só falarmos" $e$ "começarmos a agir". O nosso futuro depende do nosso presente".

"A Educação Ambiental deveria estar vinculada ao cotidiano da população, desde a relação entre a saúde e o ambiente, até a preservação dos ecossistemas. É uma questão cultural, ligada à educação da comunidade. É uma questão cultural, ligada à educação da comunidade."

"Seria interessante capacitar os professores para desenvolverem projetos ambientais com mais regularidade, independente da disciplina, pois é uma conscientização necessária. Oferecer cursos e palestras, dar sugestões de trabalhos, distribuir material do governo para o ensino médio. Muitas vezes os projetos ficam apenas na vontade, acredito que deve ser um trabalho constante."

Tabela 1: Relação das áreas de atuação dos professores com relação às questões 4, 5 e 6 do questionário.

\begin{tabular}{|c|c|c|c|}
\hline & \multicolumn{3}{|c|}{ Indagações } \\
\hline $\begin{array}{c}\text { Área de } \\
\text { Atuação }\end{array}$ & $\begin{array}{c}\text { Conhece o objetivo } \\
\text { da EA (\%) }\end{array}$ & $\begin{array}{c}\text { Tem ciência sobre a } \\
\text { imposição legal da EA } \\
(\%)\end{array}$ & $\begin{array}{c}\text { Está de acordo com a } \\
\text { importância dada ao } \\
\text { assunto (\%) }\end{array}$ \\
\hline $\begin{array}{c}\text { Ciências } \\
\text { Naturais }\end{array}$ & 100 & 40 & 100 \\
\hline $\begin{array}{c}\text { Ciências } \\
\text { Exatas }\end{array}$ & 75 & 75 & 100 \\
\hline $\begin{array}{c}\text { Ciências } \\
\text { Sociais }\end{array}$ & 89 & 78 & 100 \\
\hline $\begin{array}{c}\text { Ciências da } \\
\text { Saúde }\end{array}$ & 100 & 100 & 100 \\
\hline $\begin{array}{c}\text { Séries } \\
\text { iniciais }\end{array}$ & 100 & 100 & 100 \\
\hline
\end{tabular}

Revbea, São Paulo, V. 9, N²: 200-213, 2014. 


\section{Considerações finais}

O estudo mostra um panorama geral no qual os referidos profissionais estão inseridos. llustra a vontade da maioria, cerca de $70 \%$, entre os que se consideram aptos ou não, em atualizar-se através de um curso ou similar. Por outro lado, $11 \%$ do total de entrevistados, mostraram-se contrários a ideia de atualização, sendo que neste percentual estão os professores despreparados. O que mostra uma rejeição, mesmo que pequena, na formação continuada por parte dos mesmos.

Em relação ao Bioma Amazônia em destaque nas salas de aula, devese à ênfase dada a este ambiente pela mídia impressa e falada. Fazendo com que as pessoas sintam-se mais próximas dela, que é, sem dúvida, a maior biodiversidade do Brasil em ambiente terrestre. Em segundo lugar está o Bioma Pampa, minimizando esta disparidade, já que é o Bioma típico do Rio Grande do Sul.

Os professores que desenvolvem, de alguma maneira, a EA em sala de aula chegam a $89 \%$. E um número significante dentro desse percentual, ou seja, $16,5 \%$ indicaram seus colegas como as pessoas com menor aceitação de seus trabalhos em relação à EA. Esse quadro mostra a participação negativa e/ou a indiferença dos mesmos perante o professor que deseja trabalhar a temática. O que abre a possibilidade de uma inibição do profissional envolvido com a EA. As razões para a rejeição da temática em sala de aula são muitas, e todas levam à educação escolar tradicional.

Os resultados mostraram a unanimidade quanto à importância dada ao assunto, independente da área atuada. Um percentual considerável está informado quanto aos objetivos da EA, com uma queda no índice de professores dentro da área das ciências naturais devidamente atualizados sobre as normas jurídicas que regem a EA, como a lei №. 9.795 de 1999, por exemplo. Assim, as informações fornecidas não retratam uma imagem muito desfavorecida, obviamente que, 0 ideal seria que todos soubessem os objetivos, tivessem uma base da legislação e estivessem, de fato, de acordo com a importância dada à EA.

Contudo, indiferente aos resultados apresentados, o crédito está na aplicação da Educação Ambiental nas escolas básicas principalmente. Pois, esta é uma grande aposta para a mudança de mentalidade, e logo, de hábitos, do homem em relação ao ambiente.

\section{REFERÊNCIAS}

BIONDO, E.; OLIVEIRA, E.C.; HARRES, J.B.S.; MARCHI, M.I. "Dificuldades Percebidas Pelos Professores da Eeducação Básica do Vale do Taquai/RS na Aplicação de Projetos de Eeducação Ambiental". Revista Educação Ambiental em Ação. $N^{\circ} 34.2010$. educação ambiental: as representações dos professores de Cristalândia - TO." Revbea, São Paulo, V. 9, N²: 200-213, 2014. 
Revista Eletrônica do Mestrado em Educação Ambiental, Rio Grande, v. 18, p. 399-414, 2007.

BIZERRIL, M.X.A.; FARIA, D.S. "Percepção de professores sobre a educação ambiental no ensino fundamental". Revista brasileira Estudo pedagóico, Brasília, v. 82, n. 200/201/202, p. 57-69, jan./dez. 2001.

CORRÊA, S.A.; ECHEVERRIA, A.R.; OLIVEIRA, S.F. "A inserção dos parâmetros curriculares nacionais ( $\mathrm{PCN}$ ) nas escolas da rede pública do estado de Goiás - Brasil: a abordagem dos temas transversais - com ênfase no tema meio ambiente." Revista Eletrônica do Mestrado em Educação Ambiental, Rio Grande, v. 17, p. 01-19, 2006.

CUNHA, A. M.O.; KRASILCHIK, M. A formação continuada de professores de ciências: percepções a partir de uma experiência. Educação on-line, 2001.

DIAS, G.F. Educação ambiental: princípios e práticas. 2. ed. São Paulo: Gaia, 1993. 400 p..

GARRIDO, E.; CARVALHO, A.M.P. Discurso em sala de aula: uma mudança epistemológica e didática In: Coletânea $3^{\text {a }}$ Escola de Verão. São Paulo, FEUSP, 1995.

GUIMARÃES, M.; SOARES, A.M.D.,;CARVALHO,N.A.O.; BARRETO, M.P. "Educadores Aambientais nas Escolas: as redes como estratégia". Cadernos Cedes, Campinas, vol. 29, n. 77, p. 49-62, jan./abr. 2009.

JACOBI, P. Educação ambiental, cidadania e sustentabilidade. Caderno de Pesquisa, Mar 2003, n. 118, pág. 189-206.

KRÜGER V.; LOPES, C.V.M.; (Org.). Propostas para o Ensino de Química: Águas. Porto Alegre - RS: CECIRS, 1997.p.197.

MENDES, R.; VAZ, A. "Educação Ambiental no Ensino Formal: Narrativas de Professores Sobre suas Experiências e Perspectivas". Educação em Revistas, Belo Horizonte, vol. 25, n. 03, p. 395-411, dez. 2009.

REIGOTA, M. Desafios à educação ambiental escolar. In: Jacobi, P. et al. (orgs.). Educação, meio ambiente e cidadania: reflexões e experiências. São Paulo: SMA, 1998. p.43-50.

SANTOS, R.F. Planejamento Ambiental: teoria e prática. Oficina de textos, São Paulo. 2004.

SENICIATO, T.; CAVASSARI, O. "Aulas de campo em ambientes naturais e aprendizagem em ciências - um estudo com alunos do ensino fundamental". Ciência e Educação, Bauru, v. 10, n. 1, p. 133-47, 2004.

TRAVASSOS, E.G. A prática da educação ambiental nas escolas. 2 . ed. Porto Alegre: Mediação, 2006.

VALLE, C.E. Qualidade Ambiental: iso 14000. Editora: Senac São Paulo. Revista Atualizada. 6트. Ed. São Paulo, 2006. 
VIANA, P.A.M.O.; OLIVEIRA, J.E. "A inclusão do tema meio ambiente nos currículos escolares". Revista Eletrônica do Mestrado em Educação Ambiental, Rio Grande,v. 16, p. 01-17, 2006.

LOUREIRO, C.F.B.; LAYRARGUES, P.P.; CASTRO, R.S.C.; Educação Ambiental: repensando o espaço da cidadania. Editora: CORTEZ. $3^{\mathrm{a}}$ Ed. São Paulo - SP, 2005.

Brasil. Lei $\mathbf{N}^{\circ} \mathbf{9 . 7 9 5}$ de 27 de abril de 1999. Disponível em: <http://www.planalto.gov.br/ccivil 03/leis/l9795.htm >. Acesso em: 08 out. 2014.

Brasil. Constituição Federal de 1988. Disponível em: <http://www.planalto.gov.br/ccivil 03/constituicao/constituicaocompilado.htm >. Acesso em: 08 out. 2014.

Instituto Brasileiro de Geografia e Estatística (IBGE, 2007). Disponível em $<$ http://www.ibge.gov.br/home/presidencia/noticias/noticia visualiza.php?id noti cia $=1028 \&$ id pagina $=1>$. 


\section{APÊNDICE}

\section{ESTUDO RELACIONADO À EDUCACÃO AMBIENTAL NA ESCOLAS QUESTIONÁRIO:}

1. Você aplica aula para:
( ) Ensino Fundamental
( ) Ensino Médio

2. Em qual esfera administrativa está vinculado (a)?
( ) Estadual
( ) Municipal

3. A disciplina trabalhada é pertencente a qual ciência?
( )Ciência Natural (Biologia, Química e Geografia)
( )Ciência Social (Português, Estudo da Religião, Educação Artística e História)
( )Ciência da Saúde (Educação Física)
( ) Ciência Exata (Matemática e Física)

4. Você saberia dizer o que é e qual o objetivo da Educação Ambiental?
( ) $\operatorname{Sim}$
( ) Não

5. Você sabe que a Educação Ambiental é obrigatória, de forma articulada, nas Escolas Nacionais, por imposição legal, e em todas as disciplinas?
( ) Sim
( ) Não

6. Está de acordo com a atual importância dada a esse assunto?
( ) Sim
( ) Não

7. Você se considera capacitado para desenvolver este assunto em sala de aula?
( ) Sim
( ) Não
7.1. Independente da resposta dada:

7.1.1. Interessa-se em um curso para trocar idéias a respeito?
( ) Sim
( ) Não

8. Há a implantação da Educação ambiental em suas aulas?
( ) Sim
( ) Não

8.1. Em caso positivo:

8.1.1. Como você classificaria a aceitação dessas aulas pelos ALUNOS.
( ) Péssima ( ) Ruim
( ) Regular
( ) Boa
( ) Ótima

8.1.2. Como você classificaria a aceitação dessas aulas pelos COLEGAS de trabalho.
( ) Péssima
( ) Ruim
( ) Regular
( ) Boa
( ) Ótima

9. Qual dos Biomas Continentais Brasileiros (IBGE, 2004) você considera mais importante para abordar em sala de aula, quando o assunto é Educação Ambiental?
( ) Amazônia
( )Mata Atlântica
( ) Caatinga
( ) Cerrado
( ) Pampa
( ) Pantanal

10. Dê sua contribuição, e descreva algo que em sua opinião teria que mudar/melhorar quando abordamos Educação Ambiental. 